\title{
Who consumes whole grains, and how much?
}

\author{
Rebecca Lang* and Susan A. Jebb \\ MRC Human Nutrition Research, Elsie Widdowson Laboratory, Fulbourn Road, Cambridge CB1 9NL, UK
}

\begin{abstract}
Regular consumption of whole grain foods has been associated with a reduction in the incidence of cardiovascular disease and diabetes, reductions in cancer mortality at certain sites and an overall reduction in premature death. Although benefits are observed at relatively low levels of intake (between two and three servings per d), the consumption of whole grain foods in some Western countries is less than one serving per $d$. The main sources of whole grain are wholemeal and rye breads and whole grain breakfast cereals. Typical consumers of wholegrain foods tend to be older, from a high socio-economic group, are less likely to smoke and are more likely to exercise than non-consumers. Some of these attributes may contribute to the observed health benefits. However whole grain foods are an important source of a range of nutrients as part of a healthy eating plan. There is considerable scope for strategies to promote increased consumption of whole grain foods to reduce the risk of a variety of chronic diseases.
\end{abstract}

Whole grain: Consumption: Public health: Dietary surveys

Epidemiological evidence suggests an inverse relationship between the consumption of whole grain foods and the risk of a variety of chronic diseases. Studies have found that habitual consumption of whole grain foods is associated with reduced total mortality (Jacobs et al. 1999, 2001), cancer mortality at certain sites (Jacobs et al. 1998, 1999), risk of CHD (Liu et al. 1999), ischaemic stroke (Liu et al. 2000b) and type 2 diabetes (Liu et al. 2000a; Meyer et al. 2000). These effects have mostly been observed in large prospective population-based studies, especially within the USA, but have also been seen in smaller case-control studies looking at risk of cancer at different sites (La Vecchia et al. 1987; Tuyns et al. 1992; Chatenoud et al. 1998; Levi et al. 2000). It should be noted, however, that most of the data are derived from surveys of women alone (with the exception of Jacobs et al. 2001). Moreover, those regularly consuming whole grain foods were found to have other dietary and lifestyle habits that have been associated with good health, such as higher consumption of fruits and vegetables and an active lifestyle. Although there is a pressing need for controlled dietary intervention studies to test the health impact of increased consumption of whole grain foods, the epidemiological evidence has provided the foundation for recommendations to increase whole grain consumption.

\section{Definition of whole grain}

The three-layered structure of the whole grain contains a number of essential nutrients and non-nutrients (Slavin,
1994). The outer bran layer is rich in B vitamins and phytonutrients such as flavonoids and indoles plus a small amount of protein. The endosperm is predominantly carbohydrate, and the germ layer is a concentrated source of minerals such as $\mathrm{Fe}$ and $\mathrm{Zn}$ plus the antioxidant vitamin E. Whole grains include all three grain layers. The milling process determines how much of the whole grain is retained, with different retention levels inevitably impacting on the nutrient and non-nutrient components of the end product. At present there is no uniform definition of a whole grain food, and this situation makes it difficult to compare whole grain consumption between studies. In an analysis of British dietary surveys (Lang et al. 2001), whole grain foods were identified according to the recent US Food and Drug Administration claim that stipulates that at least $51 \%$ of a product's ingredients by weight must be whole grain, i.e. the first ingredient on the pack must be a whole grain such as whole wheat, oats, barley, rye, millet etc. (Pape et al. 1999). In contrast, many of the US studies have used foodfrequency questionnaires to assess consumption and have questioned participants about specific foods rich in whole grain, including products such as wholemeal bread, brown rice, and breakfast cereals (Jacobs et al. 1998; Liu et al. 1999, 2000a). Other studies, especially in relation to cancer risk, have been rather more imprecise and have simply highlighted fibre-rich foods such as brown bread and high-fibre breakfast cereals etc. or have separated foods into refined and unrefined varieties (Boeing et al. 1991; Bueno de Mesquita et al. 1991). At a policy level, the US Department 
Table 1. Relative risk (RR) of disease with the minimum number of daily whole grain servings

\begin{tabular}{lclcccc}
\hline Reference & Sample $(n)$ & Gender & Disease & No. of servings per d & $\mathrm{RR}$ & $95 \% \mathrm{Cl}$ \\
\hline Liu et al. $(1999)$ & 75521 & Female & CHD & $2 \cdot 7$ & 0.74 & $0.58-0.94$ \\
Liu et al. (2000a) & 75521 & Female & Type 2 diabetes & 1.3 & 0.74 & $0.64-0.86$ \\
Liu et al. (2000) & 75521 & Female & Ischaemic stroke & 1.3 & 0.60 & $0.43-0.86$ \\
Jacobs et al. (1998) & 34492 & Female & IHD & 1.2 & 0.71 & $0.51-0.98$ \\
Jacobs et al. (1999) & 34492 & Female & All-cause & \multirow{2}{*}{ Third quintile bread score } & 0.87 & $0.78-0.98$ \\
Jacobs et al. (2001) & 34492 & Male and female & All-cause & $0.71-0.92$ \\
\hline
\end{tabular}

of Agriculture (2000b) food pyramid guide identifies whole grain foods by the proportion of whole grain and non-whole grain ingredients. However, they do not specify what proportion has to be whole grain before a food is defined as a whole grain food.

In addition to the problem of defining whole grain foods, estimates of serving sizes are also inconsistent. In Finland absolute weights of products have been used and then adjusted for energy intake (Prätällä et al. 2001; Ovaskainen et al. 2001). In the UK analysis of whole grain food consumption a serving was measured as each time the food code for a whole grain food appeared in the food diary (Lang et al. 2001). This system does not reflect individual differences in portion size or the varying whole grain content of different whole grain food items, e.g. biscuits $v$. pasta. In the USA many groups have defined a serving based on portions indicated as part of the US Department of Agriculture $(2000 b)$ food guide pyramid.

\section{Recommendations for whole grain consumption}

International dietary guidelines recommend increased grain consumption. At present, the USA is the only nation to specify exact quantities of whole grain foods, and it is only within the last couple of years that whole grains have been considered separately from total grain foods. The recommendations for grains have evolved over time to reflect changes in research and to simplify and clarify consumer messages. Interestingly, the Americans do not give specific recommendations within their dietary guidelines, simply stating, 'choose a variety of grains, especially whole grains' (US Department of Agriculture, 2000a). Yet, in consumer campaigns they have promoted the 'three is key' message to provide a precise target for whole grain consumption. This recommendation of three servings per $d$ was also specifically incorporated in the Department of Health and Health Services nutrition objectives for 2010 (US Department of Health and Human Services, Public Health Service, Office of Disease Prevention and Health Promotion, 2000).

In the UK the Balance of Good Health (Food Standards Agency, 2002) has always encouraged the consumption of starchy and fibre-rich foods, but there is no specific whole grain recommendation. The recently established (UK) Food Standards Agency explicitly encourages consumers to select whole grain varieties in their healthy eating advice, although no exact quantities are given. Many other European countries also tend to place emphasis on only cereals and fibre, without necessarily specifically highlighting whole grains. The epidemiological data suggest that health benefits can be obtained at relatively low levels of whole grain consumption, typically one to three servings per d (Jacobs et al. 1998, 1999, 2001; Liu et al. 1999, 2000a,b; Table 1). In most studies there was no clear dose-response relationship, and a suggestion of a threshold effect as benefits were seen at the third quintile of whole grain intakes with no further reduction in risk as intakes increased.

\section{Consumption of whole grain foods}

Consumption of whole grain foods has been studied on a number of occasions within the USA. Albertson \& Tobelmann (1995) used food consumption data from national panel surveys based on 4000 comparable households across the USA to look at whole grain consumption (Albertson \& Tobelmann, 1995). Data were collected for $14 \mathrm{~d}$ and included any individual aged $\geq 2$ years (for reasons of comparison, only data for adults aged $>19$ years are described here). A portion was not defined, but an eating occasion including grains was used as a proxy measure and whole grains were identified separately. The authors found that $23 \%$ of the sample did not consume any whole grain foods within the recording period. Among consumers, the average serving was less than one portion per $\mathrm{d}$ and only $0.8 \%$ of the sample reached the US recommendations of three servings per d. Cleveland et al. (2000) reported similar findings in data collected from over 9000 US citizens aged $\geq 20$ years who participated in the 1994-6 US Department of Agriculture's continuing survey of food intakes (US Department of Agriculture, 1998). They used an interview technique to look at food consumption over two nonconsecutive days using servings sizes defined by the food guide pyramid. Of the sample, $29 \%$ were non-consumers and the average number of daily servings was less than one serving per $d$. However the proportion of the sample reaching the recommended three servings per $\mathrm{d}$ was $8 \%$. While it is difficult to compare the findings from these studies to examine secular trends, as quantities were not defined in the same way, these data clearly show that the consumption of whole grain foods in the USA is well below dietary recommendations.

In the UK, data from two nationally-representative surveys were recently analysed to assess whole grain consumption. The Diet and Nutritional Survey of British Adults 1986-7 included over 2000 adults aged between 16 and 64 years (Gregory et al. 1990), and the National Diet and Nutrition Survey involving individuals aged $\geq 65$ years included over 1000 free-living adults (from a total of over 2000 participants) during 1994-5 (Finch et al. 1998). 
Dietary data were collected using a $7 \mathrm{~d}$ weighed-food diary in 1986-7, and a $4 \mathrm{~d}$ weighed-food diary in 1994-5. Whole grain foods were identified as having at least $51 \%$ whole grain ingredients by weight and a serving was defined as each occasion the food appeared within the recording period. Both surveys showed approximately $30 \%$ of individuals did not consume any whole grain foods during the survey period (29\% in 1986-7 and $33.5 \%$ in 1994-5), and over $97 \%$ of adults did not meet the US recommendation of three servings per d. Median consumption was less than one serving per $d$. These findings are broadly similar to those seen in the USA (Fig. 1).

In comparison with the USA and the UK, Scandinavians consume more whole grain (Jacobs et al. 2001). In Finland rye bread has always been a staple, and consequently whole grain intakes have always been high (Pietinen et al. 1996). In Norway food disappearance data suggest that consumption of whole grain foods is four times that reported for the USA, although it is lower than that for Finland (Jacobs et al. 2001). In the Scandinavian studies, however, consumption of whole grain has not been based on the number of servings. Jacobs et al. (2001) used a bread score based on number of slices of bread consumed multiplied by the proportion of whole grain flour (based on a scored questionnaire) when assessing consumption in over 32000 Norwegian men and women. In a study of Finnish men in 1996 (Pietinen et al. 1996) the fibre content of the diet was high, which was predominantly from cereal fibre due to the high rye consumption. The range of rye-product consumption was from 28 to $161 \mathrm{~g} / \mathrm{d}$ in the lowest and highest quintiles respectively. Ovaskainen et al. (2001) used a $24 \mathrm{~h}$ recall technique with $>2500$ Finnish men and women to achieve an estimate of whole grain consumption ( $\mathrm{g}$; from rye bread), and this was then adjusted for overall energy intake, to give 11.6 and $9.3 \mathrm{~g} / \mathrm{MJ}$ per $\mathrm{d}$ for men and women respectively (total energy intakes were not provided). Prättälä et al. (2001) used a questionnaire in > 5000 Finns to look at consumption between 1978 and 1998, to provide an estimate of 'high' and 'low' users based on the number of slices of bread consumed each day. These differing techniques make it difficult to directly compare findings with the UK and USA.

\section{Demographic correlates of whole grain consumption}

A number of surveys have found an increase in whole grain consumption with age (Johansson et al. 1999; Adams \&

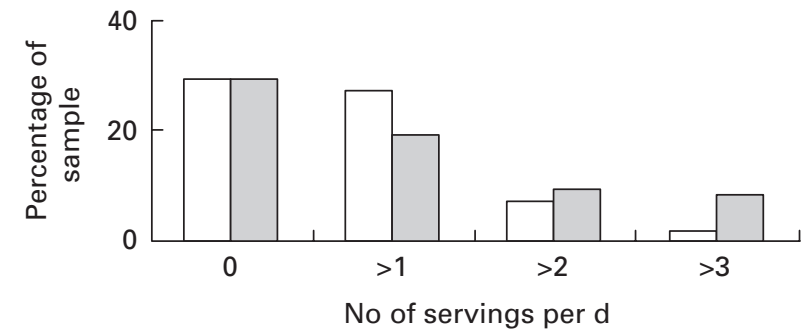

Fig. 1. Distribution of whole grain food servings per $d$ in the UK in 1986-7 ( $\square$; Lang et al. 2001) and in the USA in 1994-6 ( Cleveland et al. 2000).
Engstrom, 2000; Cleveland et al. 2000; Lang et al. 2001). For example, in the UK there was a median of one serving per week in the 16-24-year-olds rising to three servings per week in the 35-64-year-olds (1986-7 survey). Consumption in the survey of individuals aged $\geq 65$ years showed higher intakes of five servings per week (1994-5 survey), but it is not clear whether this finding reflects a secular trend or a continuing effect of age (Lang et al. 2001).

Surveys suggest that men consume more whole grain foods than women (Cleveland et al. 2000; Prättälä et al. 2001; Jacobs et al. 2001). This finding may reflect a greater food intake overall, rather than a specific preference for whole grain varieties. In the USA white adults consumed more whole grain foods than black Americans, and Mexican Americans consumed the least whole grains (Adams \& Engstrom, 2000; Cleveland et al. 2000). In the USA and UK income and level of education are also positively associated with whole grain consumption (Johansson, 1999; Adams \& Engstrom, 2000; Cleveland et al. 2000; Lang et al. 2001). However, in Finland the highest intakes of rye bread are observed in the lower socio-economic groups (Prättälä et al. 2001). In the USA and UK whole grain consumers were also less likely to smoke, tended to be regular exercisers and consumed more fruits and vegetables (Johansson, 1999; Adams \& Engstrom, 2000; Cleveland et al. 2000). These findings again confirm the association of whole grain consumption with other positive lifestyle traits (Table 2).

\section{Food sources of whole grain}

So where is the typical consumer getting their whole grains? In the UK survey of British adults, over $40 \%$ of whole grains came from whole grain varieties of bread, and just over one-third from whole grain breakfast cereals. Whole grain pasta, rice and other cereals contributed $<3 \%$ to whole grain intakes. Of the other whole grain foods, a substantial proportion came from whole grain varieties of biscuits and crackers (Lang et al. 2001). However, in absolute terms these foods are less important sources of

Table 2. Socio-demographic and lifestyle factors and wholegrain consumption in the UK (from Lang et al. 2001)

\begin{tabular}{ccc}
\hline Characteristic & NC (\% total) & $\begin{array}{c}\geq \text { three servings per d } \\
\text { (\% total) }\end{array}$ \\
\hline Gender: Male & 32.0 & 2.0 \\
Female & 27.0 & 1.0 \\
Age (years): 16-24 & 44.5 & 0.5 \\
$25-34$ & 29.5 & 0.4 \\
$35-44$ & 24.5 & 2.5 \\
$45-54$ & 29.0 & 2.0 \\
$55-64$ & 24.0 & 2.0 \\
$\geq 65$ & 33.0 & 5.0 \\
Smoking: Non-smoker & 23.0 & 2.0 \\
Smoker & 43.0 & 0.1 \\
Occupational social class: & & 2.0 \\
Non-manual & 21.5 & 0.7 \\
Manual & 39.0 & \\
\hline
\end{tabular}

NC, non-consumers. 
whole grain than bread or breakfast cereals. These proportions are broadly similar to those observed in the USA (Cleveland et al. 2000).

Using focus groups and consumer interviews, data from the USA have identified a number of reasons why consumption of whole grain foods may be low (Adams \& Engstrom, 2000). Consumers report difficulties in identifying whole grain foods (Prevention Magazine/Food Marketing Institute, 1999) and express limited knowledge about the preparation and cooking of whole grain foods (Adams \& Engstrom, 2000). Adolescents, in particular, reported that whole grain foods were bland and had a dry taste (Snow, 1999 as cited in Adams \& Engstrom, 2000). While breakfast cereals appear to be well received in this age-group, whole grain breads were described as dry and bitter. Furthermore, whole grain varieties of bread, pasta and rice tend to be more expensive (Prevention Magazine/Food Marketing Institute, 1999) and this factor may deter lowincome and vulnerable groups.

\section{Health-promotion initiatives}

Consumer research suggests that few people are aware of the health benefits of whole grain foods. Two-thirds of participants in the Market Facts Inc. (1998) survey claimed they would eat more whole grains if they knew it could lower their risk of heart disease or cancer. Although other food groups, such as fruits and vegetables, were identified as possessing health benefits, the association between whole grain foods and a reduced risk of a number of chronic diseases was not recognised. This was also the case for health professionals (Adams \& Engstrom, 2000). Recent health claims in the USA (http://www.cfsan.fda.gov/ dms/ flgrains.html) and UK (http://www.jhci.org.uk/wholegrainheart.htm) may help to address this knowledge gap. In addition, consumer initiatives such as the 'Whole Grain for Health' campaign in the UK, and 'Go Grains' in Australia provide ongoing education relating to the benefits of including whole grain products within the diet. Campaigns need to target health professionals and the food industry, as well as consumers directly, so that messages are consistent, reliable and easy to implement.

At a practical level, whole grain foods must be competitively priced and easily identified. In the UK some breakfast cereals are now clearly identifiable by a whole grain logo to help distinguish them from other high-fibre cereals. Providing serving or recipe suggestions may also encourage greater consumption of whole grains. Consumers can be encouraged to swap refined grains for whole grains, as a simple food substitution that does not require major changes in dietary habits.

In conclusion, research suggests important health benefits with regular consumption of as little as one to three servings of whole grain foods per d. However, typical consumption of whole grain foods in the USA and UK is less than one serving per $d$. Consumption of whole grain needs to be increased by reducing the proportion of non-consumers, and increasing average intakes.

\section{References}

Adams JF \& Engstrom A (2000) Dietary intake of whole grain vs. recommendations. Cereal Foods World 45, 75-79.

Albertson A \& Tobelmann R (1995) Consumption of grain and whole grain foods by an American population during the years 1990-92. Journal of the American Dietetic Association 95, 703-704.

Boeing H, Jedrychowski W, Wahrendorf J, Popiela T, TobiaszAdamczyk B et al. (1991) Dietary risk factors in intestinal and diffuse types of stomach cancer: a multicentre case-control study in Poland. Cancer Causes and Control 2, 227-233.

Bueno de Mesquita HB, Maisonneuve P, Runia S \& Moerman CJ (1991) Intake of foods and nutrients and cancer of the exocrine pancreas: a population based case-control study in The Netherlands. International Journal of Cancer 48, 540-549.

Chatenoud L, Tavani A, La Vecchia C, Jacobs DR, Negri E, Levi F \& Franceschi S (1998) Whole grain food intake and cancer risk. International Journal of Cancer 77, 24-28.

Cleveland LE, Moshfegh AJ, Albertson AM \& Goldman JD (2000) Dietary intake of whole grains. Journal of the American College of Nutrition 19, 331S-338S.

Finch S, Doyle W, Lowe C, Bates CJ, Prentice A, Smithers G \& Clarke PC (1998) National Diet and Nutrition Survey: People aged 65 Years and Over. vol. 1, Report of the Diet and Nutrition Survey. London: The Stationery Office.

Food Standards Agency (2002) The balance of good health. Leaflet FSA/0008/0201. London: Food Standards Agency.

Gregory J, Foster K, Tyler H \& Wiseman M (1990) Dietary and Nutritional Survey of British Adults. London: H.M. Stationery Office.

Jacobs DR Jr, Marquet L, Slavin J \& Kushi LH (1998) Wholegrain intake and cancer: an expanded review and meta-analysis. Nutrition and Cancer 30, 85-96.

Jacobs DR Jr, Meyer HE \& Solvoll K (2001) Reduced mortality among whole grain bread eaters in men and women in the Norwegian County Study. European Journal of Clinical Nutrition 55, 137-143.

Jacobs DR Jr, Meyer KA, Kushi LH \& Folsom AR (1999) Is whole grain intake associated with reduced total and cause-specific death rates in older women?: the Iowa Women's Health Study. American Journal of Public Health 89, 322-329.

Johansson L, Thelle D, Slovoll K, Bjoerneboe GEA \& Drevon CH (1999) Healthy dietary habits in relation to social determinants and lifestyle factors. British Journal of Nutrition 81, 211-220.

Lang R, Thane CW, Bolton-Smith C \& Jebb SA (2001) Wholegrain food consumption by British adults from two national dietary surveys. Proceedings of the Nutrition Society 60, 218A.

La Vecchia C, Negri E, Decarli A, D’Avanzo B \& Franceschi S (1987) A case-control study of diet and gastric cancer in Northern Italy. International Journal of Cancer 40, 484-498.

Levi F, Pasche C, Lucchini F, Chatenoud L, Jacobs DR \& La Vecchia C (2000) Refined and whole grain cereals and the risk of oral, oesophageal and laryngeal cancer. European Journal of Clinical Nutrition 54, 487-489.

Liu S, Manson JE, Stampfer HJ, Hu FB, Giovannucci E, Colditz GA, Manson JE, Hennekens CH \& Willett WC (2000a) A prospective study of whole grain intake and risk of type 2 diabetes mellitus in US women. American Journal of Public Health 90, 1409-1415.

Liu S, Manson JE, Stampfer HJ, Rexrode KM, Hu FB, Rimm EB \& Willett WC (2000b) Whole grain consumption and risk of ischemic stroke in women: a prospective study. Journal of the American Medical Association 284, 1534-1540. 
Liu S, Stampfer HJ, Hu FB, Giovannucci E, Rimm E, Manson JE, Hennekens CH \& Willett WC (1999) Whole grain consumption and risk of coronary heart disease: results from the Nurses' Health Study. American Journal of Clinical Nutrition 70, 412-419.

Market Facts Inc. (1998) Consumer Dietary Habits. Chicago, IL: Market Facts Inc.

Meyer KA, Kushi LH, Jacobs DR Jr, Slavin JE, Sellers TA \& Folsom AR (2000) Carbohydrates, dietary fiber, and incident type 2 diabetes in older women. American Journal of Clinical Nutrition 71, 921-930.

Ovaskainen ML, Lallukka T \& Valsta L (2001) Combinations of whole grain in the Finnish diet. In Proceedings of the VTT Symposium 213: Whole Grains and Human Health, 2001, p. 120 [K Liukkonen, A Kuokka and K Poutanen, editors]. Finland: VTT Technical Research Centre.

Pape SM, Kracov DA, Spokes JJ \& Boggs P for General Mills Inc. (1999) Whole Grain Foods Authoritative Statement Claim Notification. Washington, DC: Food and Drug Administration.

Pietinen P, Rimm EB, Korhonen P, Hartman AM, Willett WC, Albanes D \& Virtamo J (1996) Intake of dietary fiber and risk of coronary heart disease in a cohort of Finnish men. Circulation 94, 2720-2727.
Prättälä R, Helasoja V \& Mykkänen H (2001) The consumption of rye bread and white bread as dimensions of health lifestyles in Finland. Public Health Nutrition 4, 813-819.

Prevention Magazine/Food Marketing Institute (1999) Shopping for Health. Emmaus, PA: Rodale Press, Inc.

Slavin J (1994) Whole grains and health: separating the wheat from the chaff. Nutrition Today 29, 6-10.

Tuyns JA, Kaaks R, Haelterman M \& Riboli E (1992) Diet and gastric cancer. A case-control study in Belgium. International Journal of Cancer 51, 1-6.

US Department of Agriculture (1998) Continuing Survey of Food Intakes by Individuals, 1994-96. NFS Report 96-2. Washington, DC: US Department of Agriculture, Agricultural Research Service.

US Department of Agriculture (2000a) Dietary Guidelines for Americans. Dietary Guidelines Advisory Committee 2000. http://www.ars.usda.gov/dgac/2kdiet.pdf

US Department of Agriculture (2000b) The Food Guide Pyramid http://www.pueblo.gsa.gov/cic_text/food/food-pyramid/main. htm

US Department of Health and Human Services, Public Health Service, Office of Disease Prevention and Health Promotion (2000) Healthy People 2010, vols. I and II. Washington, DC: US Government Printing Office. 